Stretchers of Straw for the Dutch Army

By W. J. L. Kiehl

A NATIVE of Netherlands has invented a very practical stretcher for army use, also a field-bed of similar construction, which will be found very comfortable and warm. The stretcher consists of a mat of straw with a reinforcing of willow or reed on the underside. This is fastened to a couple of bamboo poles which serve as handles. A couple of spacing boards keep the mattress spread out fairly flat when in use, as shown in one of the drawings. A roll of straw serves as a pillow. With the bamboo poles removed the mattress of straw will be found serviceable, as a bed, even on damp ground, and a blanket, also of straw, may be used to keep the sleeper warm.

These straw stretchers were first used in conveying the wounded of the British cruisers sunk off Holland's coast, and since then they have seen service on the southern frontiers of Netherlands. Many a sick and wounded Belgian refugee or soldier has stretched his weary limbs on these straw beds. They promise to be especially useful in times of epidemic, for their inexpensiveness allows of their being burnt after use, so that there will be no danger of spreading infection. When not in use they may be rolled up and piled in stacks as shown in one of the photographs.

\section{Manufacture of Optical Glass in America}

THE glass used in this country for the manufacture of lenses is practically all imported except in the case of some of the smaller and cheaper lenses. For several years past the Bureau of Standards of the Department of Commerce has been endeavoring to persuade the glass manufacturers of the United States to take up the manufacture of this material, but they have been unable to do so, partly because of the limited quantity used as compared with other glass, but largely on account of the varying composition required and the difficulty of annealing the glass, as good optical glass must be entirely free from strain.

With a view to working out some of the underlying problems sufficiently to enable manufacturers to start in this matter, the Bureau secured two years ago an expert interested in the composition and testing of optical systems, and a little later secured another man skilled in the working of glass to the definite forms required by the theory. These steps were taken, first, partly because it is exceedingly difficult to find men having these qualifications, but principally because, as the work of experimental glass-making progresses, the glass must be put in the form of lenses and prisms to test; in other words, the Bureau had to be in a position to examine the product, as it was made experimentally. In July, 1914, a practical glass-maker wa added to the force of the Bureau. $\mathrm{He}$ is a college graduate of scientific training, but skilled in the manipulation of furnaces, and is the sort of a man to make progress at the present stage of the work.

Small furnaces were built and melts of a few pounds of ordinary glass were made in order to become more familiar with the technical side. A larger furnace has just been completed, which will handle melts of 25 to 50 pounds. The Bureau is now making glass according to definite formulas, studying the methods of securing it free from bubbles, and other practica points. This is to be followed by an investigation of the method of annealing.

Several glass manufacturers have visited the Bureau already for suggestions as to equipment for the manufacture of optical glass.

Mechanical Aids for Air Scouts

IN carrying out scouting observations $I_{\text {with military aeroplanes it is essential }}$ that there be two men in the machine namely, a pilot whose sole duty it is to

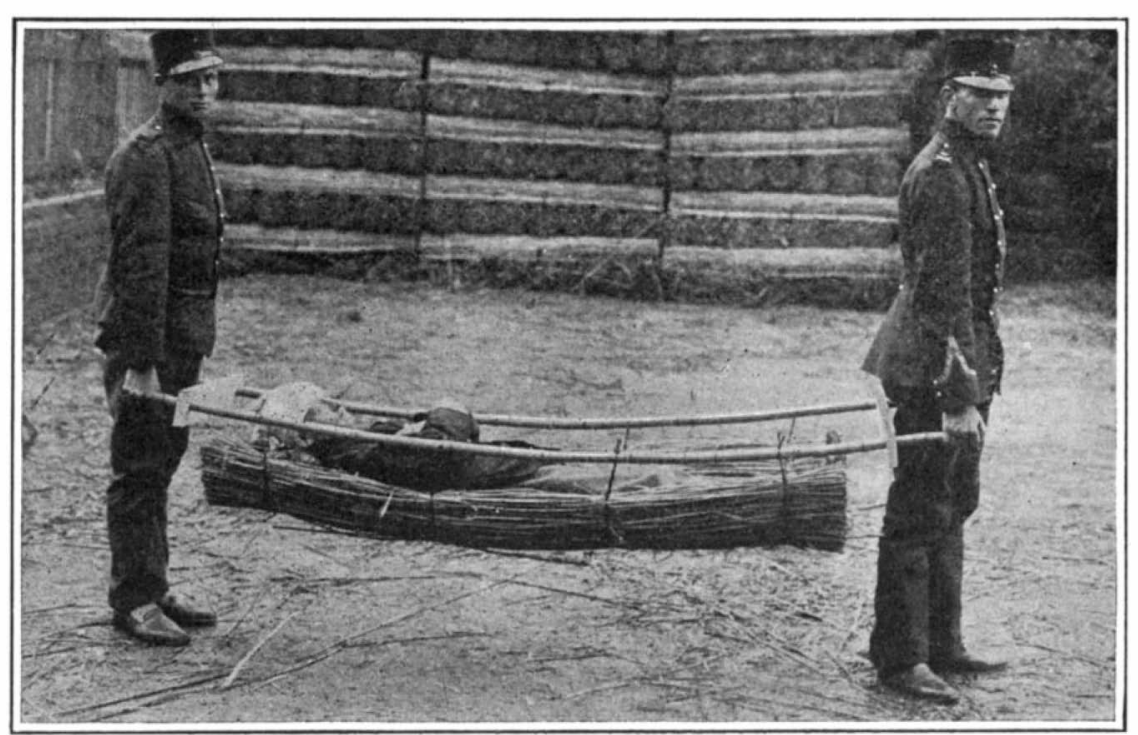

Stretcher of straw used in the Dutch army.

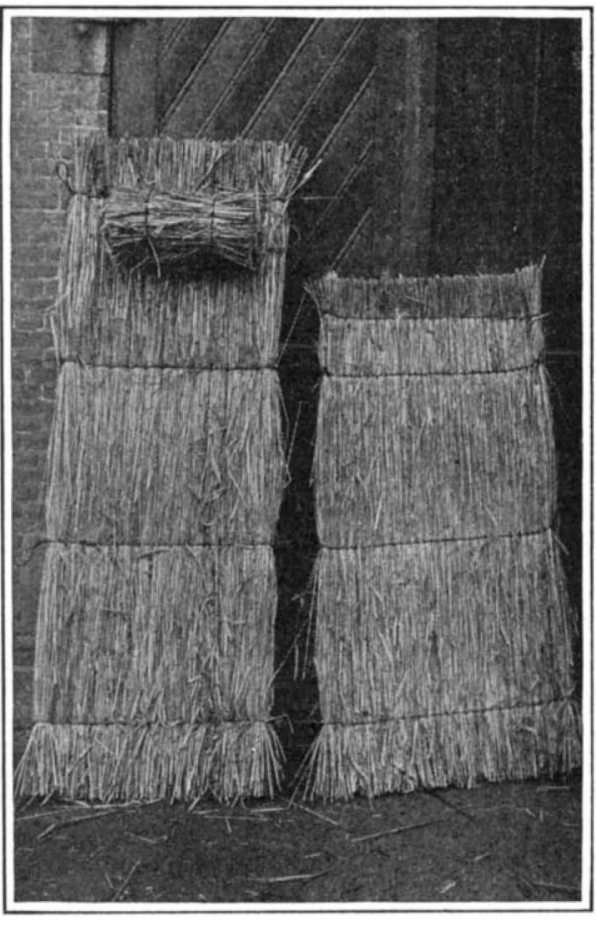

Bed, pillow, and blanket of straw.

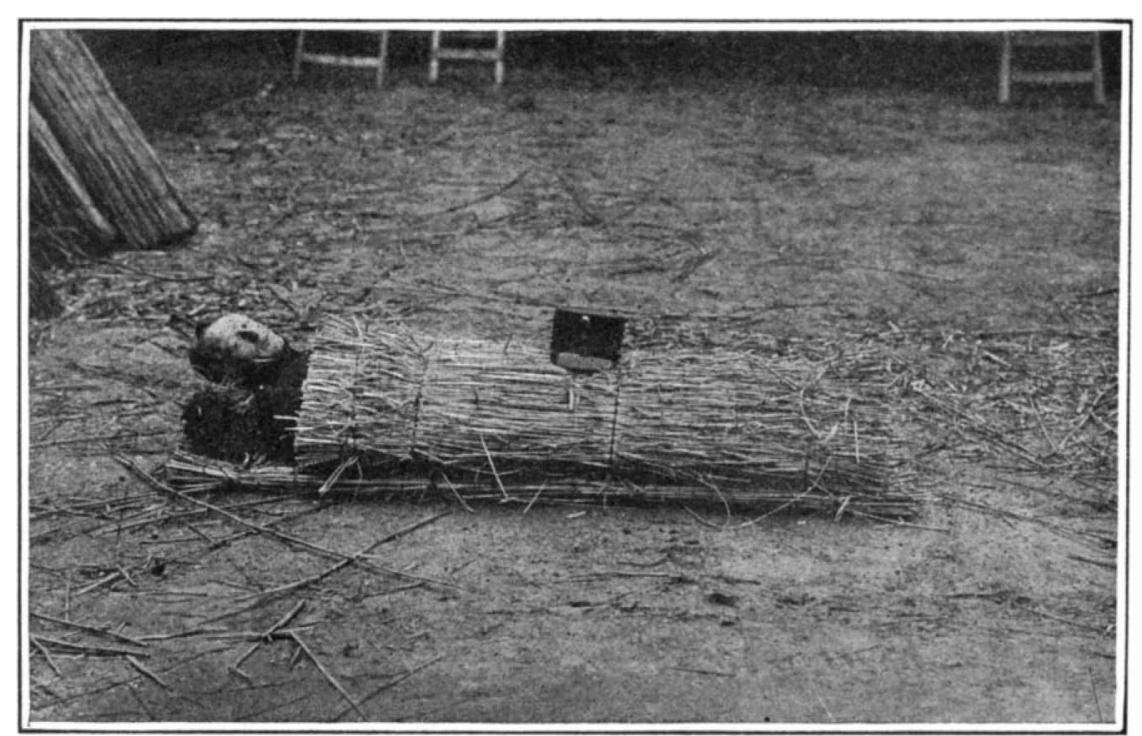

A Dutch soldier in his bed of straw.

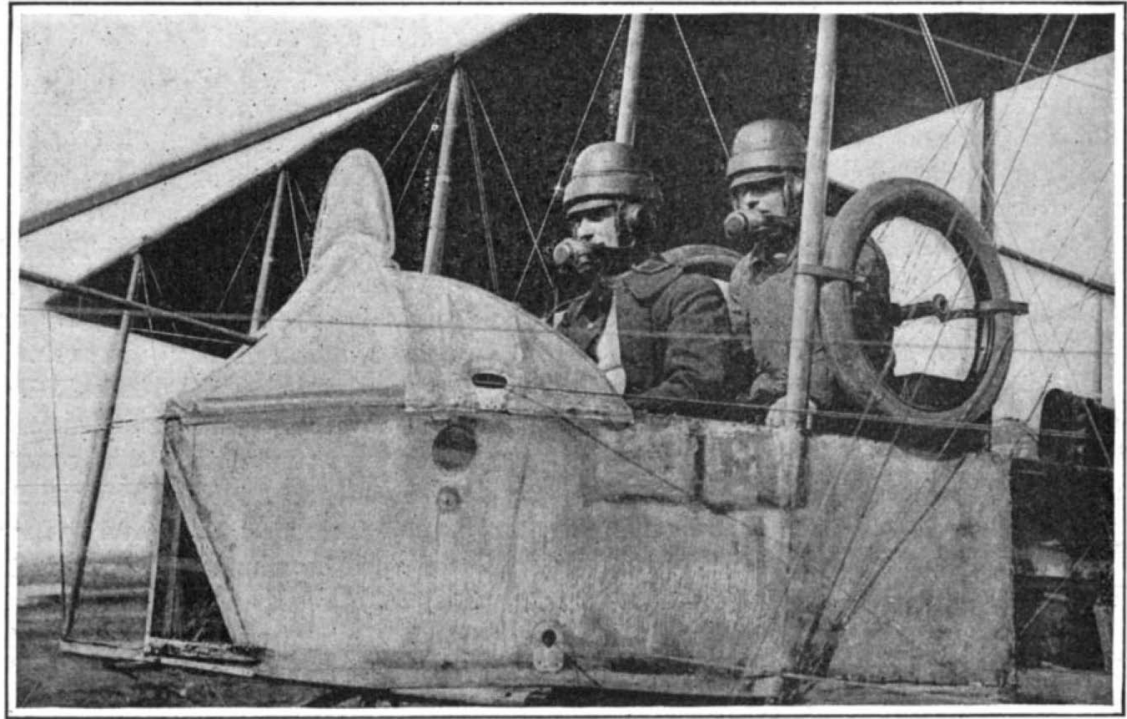

The roaring aeroplane motor makes telephone communication necessary. operate and steer the craft, and an obean devote undivided attention to scanning the ground below him and making sketches of fortified works, the disposition of the enemy's guns, the movements of their troops, and the like. Unfortunately, the great noise made by the motor renders it impossible for the two men to carry on any conversation. Often this proves quite a drawback for a proper understanding between pilot and observer. To remedy this defect a loudspeaking telephone system is now in use between pilot and observer in some of the French military aeroplanes. As the accompanying photograph shows, each man is provided with a special helmet fitted with receivers over the ears and a transmitter located in convenient range of the mouth. This has proved to be a most practical way of keeping up a conversation in spite of the deafening noise of the motor.

A still further improvement is shown in our front page illustration. If the observer is to make sketches of the ground over which he is flying, he will be so much occupied, probably, as not to have time to jot down notes. Sometimes events may follow in such rapid sequence that he may not have time to write down all he would like to. In certain conditions of flight, it might be difficult to use pencil and paper. In order to remove all obstacles that might hamper the observer's work, a phonograph is now provided, with a speaking tube running to the observer's mouth so that he may talk into the machine at any time during the flight and thus make a record of his observations, while at the same time his hands are free for the use of field glasses or the sketching pencil. At the end of the flight the phonograph delivers its message.

The Search for Standard Weights and Measures of Length

THE use of melted quartz for the manu1 facture of standard measures of length has been a great disappointment, since even this material is subject to ver marked fluctuations in length. The search for a suitable material is, however, being continued, because platinum-iridium, which has been used up to the present, is out of the question for practical purposes on account of its great cost. Dr. Guillaume discovered the alloy, which has become known under the name of "Invar," an abbreviation for "invariable." Thi nickel-steel alloy would make an ideal material for standards of length on account of its great resistance to changes in temperature, but unfortunately it is not proo against chemical action. For this reason it is suitable only for standards of the second grade, in which accuracy within a millionth part is sufficient. The ideal material, possessing the advantages of platinum-iridium, but less expensive than the latter, is therefore still to be found. Similarly good materials for standard weights have been sought extensively and variou non-magnetic nickel alloys have been tested. Among these "Constantan" has proved to be inconstant, in spite of its name.

Another alloy, "Baros," has found considerable favor. It is produced by alloying ordinary nickel with a little chromium and manganese. Still more is expected of tungsten, on account of its hardness, its great density, and its durability. For the present tungsten is still too expensive, but very likely it will be obtainable at lower prices in the near future, since it is very much in demand. A review of the progress in the use of the metric system shows that during the last six years Denmark, Siam, Belgian-Congo and some of the Central American states have adopted this decimal system. The most important success "still to be gained by the metric success "still to be gained by the metric
system, the conquest of England and of system, the conquest of England and of
the United States, seems, however, still far removed, although Dr. Guillaume himself thinks that the difficulties in the way of its adoption by these countries are much exaggerated by his opponents. 